\title{
LA EVOLUCIÓN ECONÓMICA DE MÉXICO A PARTIR DE LA REVOLUCIÓN DE 1910
}

\author{
LEOPOLDO SOLÍS \\ El Colegio de México
}

\begin{abstract}
EN EL LAPSO TRANSCURRIDO de 1910 a la fecha encontramos en la historia económica mexicana dos períodos bien diferenciados: un período sin crecimiento económico sostenido, que abarca de 1910 a 1935; y un período de crecimiento económico definido que principia en 1935 y continúa hasta nuestros días. El año de 1910 marca el inicio de una fuerte caída de la actividad económica, a excepción del auge estimulado por la primera guerra mundial, que se ve seguida por una etapa que llamaremos de formación, que se extiende de 1921 a 1935. A partír de 1935 se inicia el proceso de crecimiento económico, al principio con inflación e inestabilidad cambiaria, y el cual caracteriza el comportamiento de la economía mexicana en las dos décadas siguientes; y más tarde con estabilidad de precios y de tipo de cambio, que dura hasta la fecha. Por otra parte, en la época comprendida entre las dos guerras mundiales tiene lugar una serie de importantes cambios institucionales, que más tarde demostraron ser condiciones necesarias del proceso de crecimiento.

Los hechos anteriores aconsejan dividir el presente trabajo en tres partes, a saber: en la primera se estudiará el período armado y después el de formación (1910-35), es decir, la Revolución, el período inmediato posterior y la gran depresión de 1929-33; en la segunda se señalarán las políticas que facilitaron la formación de capital durante el período comprendido entre las dos guerras mundiales, especialmente después de la gran depresión; y en la tercera se procederá a estudiar el período de crecimiento dentro del contexto de comportamiento a largo plazo de la economía mexicana.
\end{abstract}

\section{De la Revolución de 1910 al final de la GRan Depresión}

\section{La Revolución y el periodo inmediato posterior}

Los efectos económicos directos e indirectos de la Revolución Mexicana, a corto y a largo plazo, continuarán siendo materia de discusión por largo tiempo. La destrucción de equipo de capital, sobre todo en algunas ramas, parece haber sido cuantiosa; la pérdida de vidas humanas fue también muy alta. Sin embargo, es claro que los efectos más importantes de la Revolución fueron de naturaleza política. Aunque la Revolución tuvo efectos económicos bien definidos, según veremos más adelante, éstos son difíciles de evaluar con precisión 
siguiendo el método de comparar la actual operación de la economía respecto a su comportamiento de hace más de medio siglo, toda vez que entonces se presentaba un conjunto de influencias internas y externas muy distintas a las de nuestros días. En esta materia se puede citar al profesor Clark W. Reynolds, de Ia Universidad de Stanford, quien estima que el costo de oportunidad de la Revolución fue aproximadamente de $37 \%$ en términos de ingreso no producido; costo que él juzga moderado en relación con los efectos ulteriores que propició el cambio de la estructura política, económica y social, uno de los resultados directos de aquel movimiento. ${ }^{1}$

Una forma de evaluar los efectos económicos de la Revolución, que no seguiremos aquí, consistiria en examinar el grado en que se diferencia la economía mexicana de las de otros países latinoamericanos que aún mantienen condiciones semejantes a las del México prerrevolucionario, y apreciar las diferencias de comportamiento existentes entre ellos.

Las escasas y poco confiables estadísticas y los datos existentes sobre la época armada de la Revolución indican una vertiginosa caída de la vida económica de 1910 a 1915, en todos sus aspectos. Algunas cifras ilustrarán esta afirmación. En el sector de la minería la producción sufrió un descenso sumamente brusco. La explotación de oro descendió de $41420 \mathrm{kgs}$. en 1910 a 7358 en 1915; la de plata bajó de 2417 a 1231 toneladas en los mismos años; y la de plomo experimentó un fuerte decremento, habiendo pasado de 124.3 a 5.7 toneladas en el mismo lapso. El producto bruto de la minería descendió de 1039 millones - pesos de 1950- en 1910 a 620 en 1921 (véase el cuadro 1), declinando a una tasa media anual de $4.0 \%$. Toda vez que los minerales, constituyen importantes productos de exportación, el descenso de las ventas al exterior fue especialmente severo en 1914 y 1915, años en que su valor representó aproximadamente un séptimo de los 294 millones de pesos exportados en 1910. Sin embargo, una vez derrotado el ejército federal, y con el auge de la demanda externa ocasionado por la primera guerra mundial, el valor en dólares de las exportaciones totales se recuperó rápidamente en 1916 y 1917, y pronto excedió los niveles de finales del Porfiriato, pese a que las exportaciones de productos agropecuarios y mineros descendieron de $31.6 \%$ y $5.2 \%$ del total en $1910-1911$, a $3.3 \%$ y $0.1 \%$ en 1920 ; en tanto que las exportaciones del sector petrolero pasaron de 0.2 millones de pesos en 1910-1911 a 516.8 millones en 1920, para significar el $60.4 \%$ de las exportaciones totales. De hecho, no fue sino hasta 1923 cuando la minería recuperó el valor producido en 1910. En cambio, el petróleo tuvo un crecimiento extraordinario, $43.0 \%$ anual, de 1910 a 1921. Después de producir un valor agregado casi insignificante, 33 millones en el primero de esos años, ascendió a un máximo de 1773 millones en el último, o sea tres veces el valor del producto de la minería en el mismo año. Este nivel sólo volvería a alcanzarse en 1957, con una proporción del valor generado en la refinación mucho mayor, y no, como antes, preferentemente a base de extracción.

1 Clark W. Reynolds, The Mexican Economy: Twentieth Century Structure and Growth (mimeografiado). 
Cuadro 1

México: Producto bRUto INTERno, POR SBCtoRes, 1895-1967

(Millones de pesos de 1950)

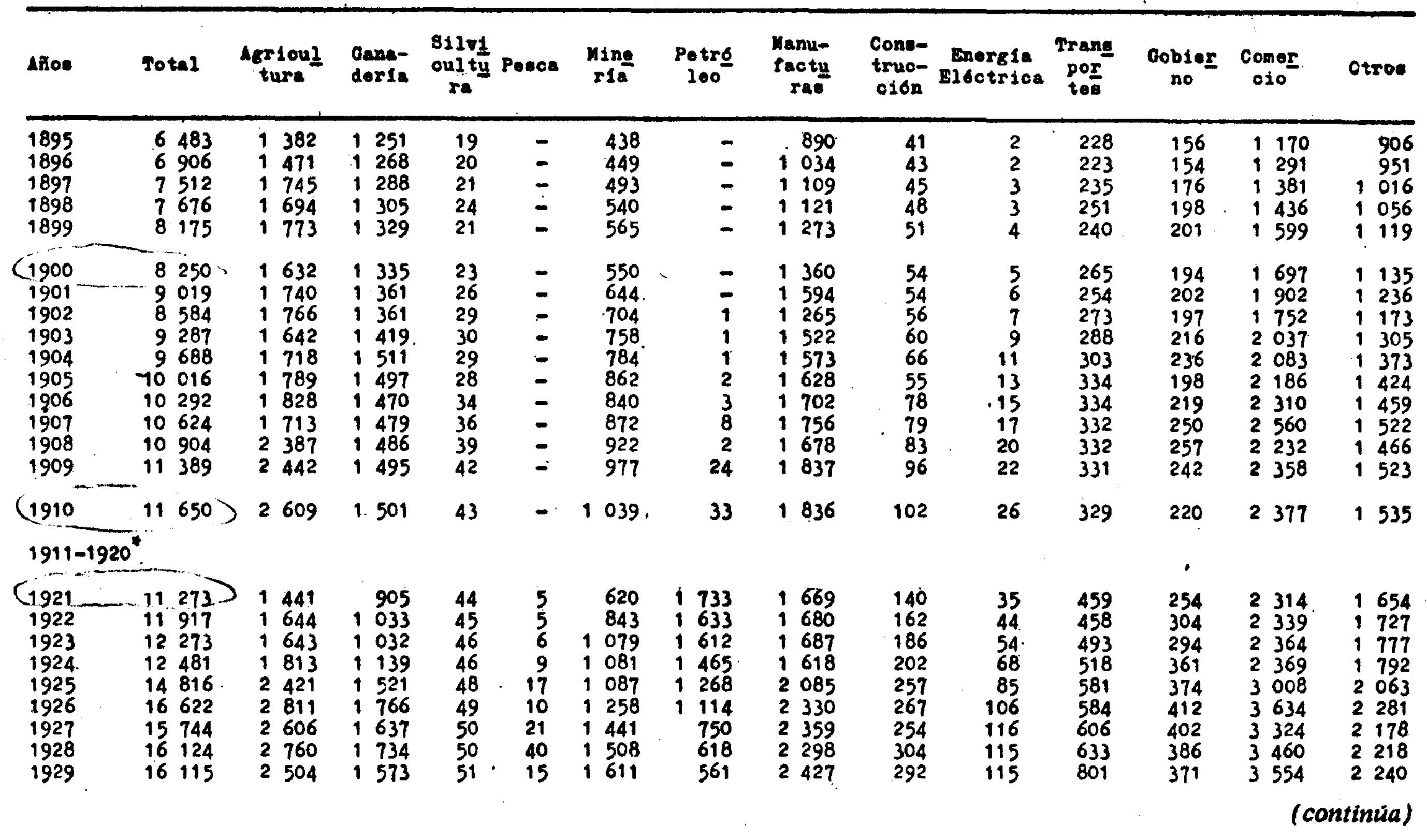


Cuadro 1 (continuacion)

\begin{tabular}{|c|c|c|c|c|c|c|c|c|c|c|c|c|c|c|}
\hline Anos & Fotal & $\begin{array}{c}\text { Agrioul } \\
\text { tura }\end{array}$ & $\begin{array}{l}\text { dana- } \\
\text { dorte }\end{array}$ & $\begin{array}{l}\text { 8xlvi } \\
\text { oul tu } \\
\text { ra }\end{array}$ & Ponoa & $\begin{array}{l}\text { Mine } \\
\text { ria }\end{array}$ & $\underset{100}{P 0 t r 6}$ & $\begin{array}{l}\text { Manu- } \\
\text { Paotu } \\
\text { rase }\end{array}$ & $\begin{array}{l}\text { Cone- } \\
\text { true- } \\
\text { oisn }\end{array}$ & $\begin{array}{l}\text { Enoricla } \\
\text { Eltotrioa }\end{array}$ & $\begin{array}{l}\text { Trans } \\
\text { por } \\
\text { tos }\end{array}$ & $\underset{\text { no }}{\text { Cobler }}$ & $\begin{array}{c}\text { Comar } \\
010\end{array}$ & Otros \\
\hline $\begin{array}{l}1930 \\
1931 \\
1932 \\
1933 \\
1934 \\
1935 \\
1936 \\
1937 \\
1938 \\
1939\end{array}$ & $\begin{array}{ll}15 & 540 \\
16 & 016 \\
13 & 547 \\
15 & 759 \\
16 & 647 \\
17 & 983 \\
19 & 492 \\
20 & 547 \\
20 & 918 \\
22 & 623\end{array}$ & $\begin{array}{ll}2 & 283 \\
2 & 647 \\
2 & 565 \\
2 & 940 \\
2 & 689 \\
2 & 904 \\
3 & 202 \\
3 & 224 \\
3 & 322 \\
3 & 239\end{array}$ & $\begin{array}{ll}1 & 434 \\
1 & 647 \\
1 & 632 \\
1 & 617 \\
1 & 876 \\
1 & 975 \\
2 & 071 \\
2 & 124 \\
2 & 087 \\
2 & 035\end{array}$ & $\begin{array}{r}42 \\
60 \\
86 \\
123 \\
255 \\
113 \\
109 \\
94 \\
139 \\
175\end{array}$ & $\begin{array}{r}14 \\
9 \\
10 \\
8 \\
16 \\
15 \\
14 \\
16 \\
24 \\
20\end{array}$ & $\begin{array}{ll}1 & 458 \\
1 & 272 \\
882 \\
\\
1 & 920 \\
1 & 095 \\
1 & 136 \\
1 & 191 \\
1 & 360 \\
1 & 367 \\
1 & 263\end{array}$ & $\begin{array}{l}552 \\
449 \\
463 \\
511 \\
609 \\
623 \\
582 \\
666 \\
645 \\
603\end{array}$ & $\begin{array}{ll}2 & 416 \\
2 & 296 \\
1 & 682 \\
2 & 235 \\
2 & 427 \\
2 & 820 \\
3 & 197 \\
3 & 281 \\
3 & 422 \\
3 & 999\end{array}$ & $\begin{array}{l}301 \\
265 \\
223 \\
317 \\
407 \\
354 \\
-486 \\
571 \\
596 \\
409\end{array}$ & $\begin{array}{l}122 \\
125 \\
125 \\
128 \\
153 \\
173 \\
188 \\
207 \\
210 \\
206\end{array}$ & $\begin{array}{l}793 \\
747 \\
677 \\
586 \\
811 \\
759 \\
828 \\
918 \\
909 \\
827\end{array}$ & $\begin{array}{l}368 \\
339 \\
344 \\
377 \\
408 \\
447 \\
573 \\
571 \\
575 \\
880\end{array}$ & $\begin{array}{ll}3 & 585 \\
3 & 944 \\
2 & 984 \\
3 & 817 \\
3 & 598 \\
4 & 176 \\
4 & 354 \\
4 & 672 \\
4 & 728 \\
5 & 837\end{array}$ & $\begin{array}{ll}2 & 172 \\
2 & 216 \\
1 & 874 \\
2 & 180 \\
2 & 303 \\
2 & 488 \\
2 & 697 \\
2 & 843 \\
2 & 894 \\
3 & 130\end{array}$ \\
\hline $\begin{array}{l}1940 \\
1941 \\
1942 \\
1943 \\
1944 \\
1945 \quad 6.0 \\
-1946 \\
1947 \\
1948 \\
1949 \ldots\end{array}$ & $\left(\begin{array}{ll}22 & 8899) \\
25 & 136 \\
26 & 696 \\
27 & 554 \\
29 & 563 \\
30 & 473 \\
32 & 477 \\
33 & 761 \\
35 & 278 \\
-37 & 424\end{array}\right)$ & $\left(\begin{array}{ll}2 & 898 \\
3 & 539 \\
3 & 989 \\
3 & 629 \\
3 & 983 \\
3 & 815 \\
3 & 857 \\
4 & 247 \\
4 & 709 \\
5 & 405\end{array}\right.$ & $\begin{array}{ll}2 & 070 \\
2 & 203 \\
2 & 218 \\
2 & 256 \\
2 & 264 \\
2 & 378 \\
2 & 552 \\
2 & 526 \\
2 & 758 \\
2 & 839\end{array}$ & $\begin{array}{l}180 \\
185 \\
239 \\
244 \\
241 \\
202 \\
231 \\
165 \\
167 \\
161\end{array}$ & $\begin{array}{l}23) \\
19 \\
26 \\
32 \\
36 \\
42 \\
45 \\
49 \\
62 \\
80\end{array}$ & $\begin{cases}1 & 241 \\
1 & 211 \\
1 & 386 \\
1 & 417 \\
1 & 231 \\
1 & 263 \\
& 975 \\
1 & 274 \\
1 & 176 \\
1 & 183\end{cases}$ & $\begin{array}{l}574 \\
587 \\
544 \\
565 \\
570 \\
646 \\
724 \\
824 \\
900 \\
942\end{array}$ & $\begin{array}{ll}4 & 264 \\
4 & 650 \\
5 & 014 \\
5 & 296 \\
5 & 709 \\
5 & 915 \\
6 & 469 \\
6 & 575 \\
6 & 989 . \\
7 & 491\end{array}$ & $\begin{array}{l}497 \\
514 \\
\\
547 \\
\\
582 \\
704 \\
\\
115 \\
1093 \\
11115 \\
11080 \\
1093\end{array}$ & $\begin{array}{l}212 \\
211 \\
219 \\
229 \\
230 \\
257 \\
277 \\
301 \\
332 \\
362\end{array}$ & $\begin{array}{ll} & 865 \\
& 930 \\
1 & 024 \\
1 & 167 \\
1 & 248 \\
1 & 328 \\
1 & 479 \\
1 & 602 \\
1 & 728 \\
1 & 873\end{array}$ & $\begin{array}{l}898 \\
907 \\
906 \\
999 \\
1190 \\
11215 \\
1002 \\
11146 \\
1223 \\
12205\end{array}$ & $\begin{array}{ll}5 & 919 \\
6 & 740 \\
6 & 995 \\
7 & 337 \\
8 & 170 \\
8 & 333 \\
9 & 348 \\
9 & 343 \\
9 & 391 \\
9 & 757\end{array}$ & $\begin{array}{ll}3 & 248 \\
3 & 440 \\
3 & 589 \\
3 & 801 \\
3 & 997 \\
4 & 164 \\
4 & 425 \\
4 & 594 \\
4 & 763 \\
5 & 033\end{array}$ \\
\hline $\begin{array}{l}1950 \\
1951 \\
1952 \\
1953 \\
1954 \\
1955 \\
1956 \\
1957 \\
1958 \\
1959\end{array}$ & $\begin{array}{ll}41 & 0607 \\
44 & 217 \\
45 & 939 \\
46 & 029 \\
50 & 859 \\
55 & 312 \\
58 & 962 \\
63 & 431 \\
66 & 918 \\
66 & 852\end{array}$ & $\begin{array}{ll}25 & 999 \\
6 & 299 \\
6 & 017 \\
6 & 053 \\
7 & 571 \\
6 & 417 \\
7 & 931 \\
8 & 669 \\
9 & 430 \\
8 & 711\end{array}$ & $\begin{array}{ll}2 & 903 \\
3 & 109 \\
3 & 222 \\
3 & 164 \\
3 & 315 \\
3 & 460 \\
3 & 603 \\
3 & 893 \\
4 & 076 \\
4 & 233\end{array}$ & $\begin{array}{l}263 \\
267 \\
209 \\
208 \\
226 \\
256 \\
255 \\
243 \\
225 \\
254\end{array}$ & $\begin{array}{r}77 \\
73 \\
61 \\
70 \\
70 \\
86 \\
102 \\
94 \\
108 \\
122\end{array}$ & $\begin{array}{ll}1 & 243 \\
1 & 198 \\
1 & 330 \\
1 & 316 \\
1 & 240 \\
1 & 437 \\
1 & 452 \\
1 & 547 \\
1 & 539 \\
1 & 587\end{array}$ & $\begin{array}{ll}1 & 129 \\
1 & 242 \\
1 & 310 \\
1 & 330 \\
1 & 432 \\
1 & 545 \\
1 & 648 \\
1 & 756 \\
1 & 962 \\
2 & 224\end{array}$ & $\begin{array}{rr}8 & 437 \\
9 & 332 \\
9 & 744 \\
9 & 632 \\
10 & 575 \\
11 & 605 \\
12 & 915 \\
13 & 763 \\
14 & 500 \\
15 & 800\end{array}$ & $\begin{array}{ll}1 & 287 \\
1 & 409 \\
1 & 587 \\
1 & 465 \\
1 & 577 \\
1 & 757 \\
2 & 028 \\
2 & 295 \\
2 & 216 \\
2 & 265\end{array}$ & $\begin{array}{l}370 \\
411 \\
447 \\
477 \\
526 \\
586 \\
655 \\
707 \\
761 \\
818\end{array}$ & $\begin{array}{ll}1 & 988 \\
2 & 179 \\
2 & 403 \\
2 & 479 \\
2 & 658 \\
2 & 851 \\
3 & 159 \\
3 & 298 \\
3 & 403 \\
3 & 507\end{array}$ & $\begin{array}{ll}1 & 294 \\
1 & 378 \\
1 & 466 \\
1 & 492 \\
1 & 563 \\
1 & 599 \\
1 & 694 \\
1 & 815 \\
1 & 837 \\
1 & 892\end{array}$ & $\begin{array}{ll}10 & 750 \\
11 & 793 \\
12 & 147 \\
12 & 427 \\
13 & 169 \\
14 & 233 \\
15 & 157 \\
16 & 318 \\
17 & 157 \\
17 & 608\end{array}$ & $\begin{array}{ll}5 & 320 \\
5 & 527 \\
5 & 996 \\
5 & 916 \\
6 & 937 \\
7 & 480 \\
8 & 363 \\
9 & 033 \\
9 & 704 \\
9 & 831\end{array}$ \\
\hline
\end{tabular}




\begin{tabular}{|c|c|c|c|c|c|c|c|c|c|c|c|c|c|c|c|}
\hline คñ๊o & Tot & a & $\left\{\begin{array}{c}\text { Aerjoul } \\
\text { tura }\end{array}\right.$ & $\begin{array}{l}\text { Oana- } \\
\text { deria }\end{array}$ & $\begin{array}{l}\text { Silvi } \\
\text { oultu } \\
\text { re }\end{array}$ & Ponos & $\operatorname{ming}_{\text {ria }}$ & $\underset{200}{\text { Potro }}$ & $\begin{array}{c}\text { Yanu- } \\
\text { faotu } \\
\text { ras }\end{array}$ & $\begin{array}{l}\text { Cone- } \\
\text { truo- } \\
\text { ol } 6 \text { in }\end{array}$ & $\begin{array}{l}\text { Mnorgla } \\
\text { Elcotrioa }\end{array}$ & $\begin{array}{c}\text { Trane } \\
\text { pox } \\
\text { too }\end{array}$ & $\begin{array}{c}\text { Dobser } \\
\text { no }\end{array}$ & Cosor & ctrov \\
\hline \multirow[t]{2}{*}{$\begin{array}{r}1960 \\
1061 \\
1962 \\
1963 \\
1964 \\
1965 \\
1966 \\
-1967\end{array}$} & $\begin{array}{r}174 \\
76 \\
80 \\
85 \\
94 \\
99 \\
107 \\
114\end{array}$ & $\begin{array}{l}312 \\
927 \\
742 \\
865 \\
601 \\
61613 \\
238 \\
154\end{array}$ & $\begin{cases}9 & 178 \\
9 & 417 \\
10 & 013 \\
10 & 163 \\
10 & 986 \\
11 & 579 \\
11 & 764 \\
12 & 000\end{cases}$ & $\begin{array}{ll}4 & 450 \\
4 & 624 \\
4 & 779 \\
4 & 922 \\
5 & 094 \\
5 & 267 \\
5 & 478 \\
5 & 670\end{array}$ & $\begin{array}{l}254 \\
228 \\
236 \\
258 \\
277 \\
279 \\
277 \\
298\end{array}$ & $\begin{array}{l}136 \\
147 \\
147 \\
155 \\
155 \\
147 \\
160 \\
173\end{array}$ & $\begin{array}{ll}1 & 648 \\
1 & 579 \\
1 & 599 \\
1 & 655 \\
1 & 670 \\
1 & 657 \\
1 & 700 \\
1 & 729\end{array}$ & $\begin{array}{ll}2 & 346 \\
2 & 613 \\
2 & 662 \\
2 & 827 \\
3 & 084 \\
3 & 214 \\
3 & 317 \\
3 & 698\end{array}$ & $\begin{array}{ll}17 & 116 \\
17 & 726 \\
18 & 862 \\
20 & 597 \\
23 & 523 \\
25 & 202 \\
27 . & 999 \\
30 & 240\end{array}$ & $\begin{array}{ll}2 & 595 \\
2 & 620 \\
2 & 649 \\
3 & 065 \\
3 & 568 \\
3 & 507 \\
4 & 033 \\
4 & 456\end{array}$ & 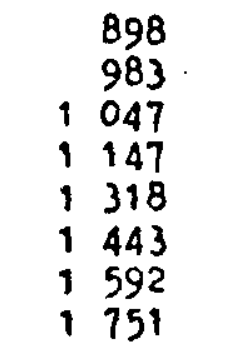 & $\begin{array}{ll}3 & 638 \\
3 & 664 \\
3 & 671 \\
3 & 830 \\
4 & 066 \\
4 & 265 \\
4 & 448 \\
4 & 670\end{array}$ & $\begin{array}{ll}1 & 985 \\
2 & 129 \\
2 & 264 \\
2 & 382 \\
2 & 620 \\
2 & 725 \\
2 & 891 \\
3 & 036\end{array}$ & $\begin{array}{ll}19 & 167 \\
19 & 780 \\
20 & 769 \\
22 & 077 \\
24 & 461 \\
25 & 806 \\
27 & 870 \\
29 & 654\end{array}$ & $\begin{array}{ll}10 & 906 \\
11 & 417 \\
12 & 044 \\
12 & 787 \\
13 & 779 \\
14 & 525 \\
15 & 709 \\
16 & 779\end{array}$ \\
\hline & \multicolumn{15}{|c|}{ Tasal medias de oreoimiento anual } \\
\hline \multicolumn{2}{|c|}{$\begin{array}{r}1895-1900 \\
1901-1910 \\
1911-1921 \\
-1922-1935 \\
1936-1956 \\
1957-1967 \\
1895-1910 \\
1921-1967\end{array}$} & $\begin{array}{r}4.9 \\
3.5 \\
-0.3 \\
3.4 \\
5.8 \\
6.2 \\
3.6 \\
5.2\end{array}$ & $\begin{array}{r}3.4 \\
4.8 \\
-5.2 \\
5.1 . \\
4.9 \\
3.8 \\
2.3 \\
4.7\end{array}$ & $\begin{array}{r}1.3 \\
1.2 \\
-4.6 \\
5.7 \\
2.9 \\
4.2 \\
1.2 \\
4.1\end{array}$ & $\begin{array}{l}3.9 \\
6.5 \\
0.2 \\
7.0 \\
4.0 \\
1.4 \\
5.7 \\
4.2\end{array}$ & $\begin{array}{l}- \\
= \\
8.2 \\
9.6 \\
4.9 \\
8.0\end{array}$ & $\begin{array}{r}4.2 \\
6.6 \\
-4.6 \\
4.4 \\
1.2 \\
1.6 \\
5.9 \\
2.3\end{array}$ & $\begin{array}{c}54.01 \\
43.0 \\
-7.1 \\
4.7 \\
7.6 \\
-5\end{array}$ & $\begin{array}{r}8.9 \\
3.1 \\
-0.9 \\
3.8 \\
7.5 \\
8.0 \\
4.9 \\
6.5\end{array}$ & $\begin{array}{l}5.7 \\
6.6 \\
2.2 \\
6.8 \\
8.7 \\
7.4 \\
6.3 \\
7.8\end{array}$ & $\begin{array}{r}20.0 \\
17.9 \\
0.7 \\
12.1 \\
6.5 \\
9.4 \\
18.7 \\
8.9\end{array}$ & $\begin{array}{l}3.1 \\
2.2 \\
3.1 \\
3.7 \\
7.0 \\
3.6 \\
2.5 \\
5.2\end{array}$ & $\begin{array}{l}4.50 \\
1.3 \\
1.3 \\
4.1 \\
6.5 \\
5.4 \\
2.3 \\
5.5\end{array}$ & $\begin{array}{r}7.7 \\
3.4 \\
-0.2 \\
4.3 \\
6.3 \\
6.3 \\
4.8 \\
5.7\end{array}$ & $\begin{array}{r}4.6 \\
3.1 \\
-0.7 \\
2.9 \\
5.9 \\
6.5 \\
3.6 \\
5.2\end{array}$ \\
\hline
\end{tabular}

Fuente: En el periodo 1895-1938, para la estimación de la producción de los sectores se trató de seguir, hasta donde la información existente lo permitió, la metodología empleada por el Banco de México; a excepción de los sectores minería, petróleo, manufacturas y transportes, en cuya estimación se utilizaron las series presentadas por Enrique Pérez López en México: 50 años de Revolución. I. La economía. Las personas interesadas en conocer detalladamente la meto dología seguida en estas estimaciones, pueden solicitarla por escrito y les será enviada. Para el periodo 1939-1950, Banco de México, Departamento de Estudios Económicos, Producto Nacional Bruto, Revisión de las estimaciones para los años 1939-1949, diciembre 17 de 1964; período 1950-1966; Banco de México, Departamento de Estudios Económicos, Estadísticas de Producción Nacional 1950-1966, 22 de febrero de 1967; 1967 preliminar.

Nota: - * Datos no dísponibles.

1 Corresponde al período $1903-1910$. 
Los productos agrícolas más importantes no muestran en un amplio número cambios considerables de nivel de producción entre 1910 y 1925. Tal es el caso del maíz, el frijol, la caña de azúcar, el chile seco, el café y el henequén. Un número reducido de productos acusó en 1925 volúmenes de producción inferiores a los del Porfiriato, niveles que sólo fueron alcanzados nuevamente después de la gran depresión de 1929-1933; tales fueron los casos del cacao y el tabaco. El arroz muestra un ascenso en los volúmenes cosechados de 1910 a 1925, como resultado de la destrucción de los ingenios azucareros, especialmente de la zona de Morelos. En resumen, el producto bruto agrícola, que había crecido al ritmo de $4.4 \%$ anual en 1895-1910, descendió a 1441 millones en 1921, o sea un descenso medio anual de $5.2 \%$. La ganadería, por su parte, descendió al $4.6 \%$ anual.

La producción manufacturera, que creció al $4.9 \%$ anual en 18951910, señala una situación similar a la de la producción agrícola. El indice de volumen registra descensos pocas veces interrumpidos de 1910 a 1918, sin haber alcanzado nuevamente los niveles de 1910 hasta aproximadamente $1922 . .^{2} \mathrm{El}$ valor agregado en las manufacturas, 1836 millones (pesos de 1950) en 1910, descendió a 1669 millones en 1921, o sea el $0.9 \%$ anual. Resulta interesante señalar que toda la actividad industrial (manufacturas, construcción y electricidad) producía, tanto en 1910 como en 1921, un valor agregado inferior (aproximadamente la mitad) al del sector agropecuario en las mismas fechas, y al de la minería y el petróleo; pero su crecimiento en la década de los veintes fue bastante acelerado y en 1929 superaba a las industrias extractivas, aunque su valor resultaba bastante inferior aún al del sector agropecuario. Sin embargo, como este último sector se estancó hasta la época cardenista, desde 1929, y especialmente en la segunda mitad de los treintas, las manufacturas superaron en participación relativa a la agricultura, proceso que se habría de acentuar hasta nuestros días.

Se puede comparar detalladamente la situación económica del país de finales del Porfiriato con la del de principios de la etapa constructiva de la Revolución, 1925 - cuando se comenzaron a crear las instituciones y mecanismos de fomento económico a los que se hará referencia más adelante-, revisando la situación de la balanza de pagos en el trabajo de G. Butler Sherwell sobre la capacidad de México para pagar la deuda externá. ${ }^{3}$

Este autor señala que entre 1921 y 1928 México conservó una balanza comercial favorable, la cual, hacia el final de ese período, tuvo un saldo positivo cercano al $80 \%$ del valor de las importaciones. En cambio, en 1909-1910 dicho saldo favorable había consistido aproximada. mente en sólo el $30 \%$ del valor de las importaciones. De manera que después de la Revolución aumentó el volumen de recursos internos que se transfería al exterior. Dicho saldo, del que Butler Sherwell deduce el valor enviado al exterior y al que agrega la importación de

\footnotetext{
2 Secretarfa de Economía, Dirección General de Estudios Económicos, Trimestre de Barómetros Económicos, Núm. 8, marzo de 1948, pp. 45-46.

3 G. Butler Shervell, Mexico's Capacity to Pay. A General Analysis of the Present International Economic Position of Mexico, Washington, 1929 (mimeo-
rrafiado).
} 
capital no destinado a la inversión, era inferior a las remisiones de fondos al exterior consistentes en envíos por concepto de dividendos de la inversión extranjera, servicio de las deudas públicas, federal, estatal y municipal, pagos a compañias de seguros, envíos a agentes del go bierno en el exterior y remisiones de otro género.

El saldo comercial fue también más favorable en 1926, apoyadö en parte por remisiones de mexicanos emigrados a los Estados Unidos y por el comienzo de los ingresos por turismo. En la cuenta de capital, el servicio de la deuda pública fue casi igual en 1910 y 1926, habiendo bajado las remisiones por ferrocarriles y bancos y ascendido los envíos de intereses, regalías, etc., de las compañías petroleras e industrias varias. El déficit global fue cubierto con nuevas inversiones extranjeras, especialmente en petróleo (aunque su valor total fue muy inferior al de 1910) y con reinversiones de las mismas (aproximadamente 100 millones de pesos); de modo que pese a la transferencia de ahorros al exterior, el valor de la inversión extranjera en el país aumentaba. De cualquier manera, el país perdía divisas y la cotización del peso declinó en 1926.

En 1921 el valor de las exportaciones fue casi tres veces superior al de 1910; de aquel año hasta 1926 descendió debido a la baja en las exportaciones de petróleo. Las exportaciones de productos agrícolas (compuestas principalmente de henequén, vegetales frescos y secos, café, algodón -el consumo interno de algodón descendió entre 1910 y 1926-, chicle, garbanzo, ixtle, plátano, hule y guayule, etc.) descendieron fuertemente en términos absolutos, y más aún como proporción de las exportaciones totales, habiendo pasado de $31.6 \%$ del total en 1910 a $3.3 \%$ en 1921. Sin embargo, algunas ascendieron como resultado de la introducción y expansión del tomate y del incremento en el volumen exportado de garbanzo, henequén y café. La exportación de ganado descendió a 193.3 miles de cabezas en 1926 a causa de la destrucción y exportación de ganado durante la Revolución; la baja se apreció también en los cueros exportados. Los envíos de manufacturas al exterior descendieron poco, aunque los de algunas, como el azúcar, lo hicieron en forma bastante brusca.

El aumento de las exportaciones de minerales se explica casi en su totalidad por el desarrollo de la industria petrolera. El resto del ascenso en la exportación de este renglón refleja cambios en los precios de los minerales exportados en 1926 respecto a sus cotizaciones en 1910; así como aumentos en el tonelaje exportado de plomo y zinc, principalmente, y de cobre, aunque en menor cuantía.

Las exportaciones de minerales industriales significaron casi el total de la producción en 1926. En ese año ya las empresas extranjeras dominaban la explotación de productos minerales en mayor medida que en 1910, debido a que las grandes empresas mineras norteamericanas compraron durante la Revolución los intereses de pequeños productores mexicanos. Lo mismo ocurrió en actividades comerciales e industriales. Por ejemplo, en 1926 el $98 \%$ de la industria textil era extranjera. Butler Sherwell señala que de 1910 a 1926 aumentó considerablemente el número de empresas comerciales en manos de norteamericanos.

Entre 1910 y 1926 las compras al exterior ascendieron en forma 
similar a las exportaciones totales, como resultado del incremento de la capacidad para importar. Las compras de alimentos (vegetales y animales) ganaron importancia como consecuencia de los trastornos en la producción agrícola durante el movimiento armado, toda vez que la población campesina descendió en forma notable. La manteca y los cereales fueron algunos de los productos importados cuyo valor ascendió rápidamente, de tal manera que en 1921 las importaciones de bienes agropecuarios fueron casi iguales a las exportaciones de los mismos. El incremento en las adquisiciones de productos minerales se debió a las compras de derivados del petróleo; en el de los textiles, a los artículos de lana, ya que México era fuerte importador de hilados, tejidos y acabados de fibras blandas. Las importaciones de maquinaria y vehículos se debieron fundamentalmente al desarrollo de las industrias petrolera y automotriz.

Debe recordarse que la población descendió en aproximadamente un millón de personas entre 1910 y 1921, habiendo pasado en ese lapso de 15.2 a 14.3 millones. Además de las defunciones directamente atribuibles a la Revolución, y al probable descenso de la natalidad, también consecuencia de la misma, hubo otros elementos que condicionaron la baja de la población. En 1910 cerca de 200000 personas nacidas en México vivían en los Estados Unidos; durante los siguientes veinte años los emigrantes mexicanos al país del norte se cuadruplicaron. Otro elemento que ayuda a explicar el descenso de la población es la epidemia de influenza que azotó al país en 1918-1919 y fue responsable de víctimas tanto entre la población urbana como en la rural. La emigración y las bajas atribuibles a la influenza deben de haber eliminado a las personas del más bajo nivel cultural, pues según el censo de 1921, los índices educativos muestran una mejoría respecto a los de 1910; en este último año 3.6 millones de personas sabían leer y escribir, frente a 3.0 millones en 1910 .

\section{La depresión de 1929-1933}

La gran crisis de 1929 influyó para deprimir los niveles de actividad económica. El valor de las exportaciones, que descendió en el periodo de 1926 a 1929 como resultado de la continuación de la baja en la producción de petróleo, se abatió aún más rápidamente, hasta registrar en 1932 casi un tercio de su valor de 1929; la importación descendió en proporción similar, habiendo alcanzado un valor en dólares corrientes inferior al de principios de siglo. Como una parte importante ( $25 \%$ aproximadamente) de las recaudaciones impositivas dependía de los impuestos al comercio exterior, los ingresos federales descendieron en una cuarta parte de 1930 a 1933, razón por la cual la política fiscal actuó para nivelar el presupuesto bajando los gastos federales. Las erogaciones disminuyeron una cuarta parte de 1930 a 1932, nivel sólo ligeramente inferior al de los ingresos durante el mismo año. De hecho, la inversión pública federal descendió de 103 a 73 millones de pesos corrientes de 1930 a 1932, habiendo afectado

\&a situación fiscal había cambiado en cierta medida de 1910 a 1926; las tasas impositivas al comercio exterior se elevaron y en 1924 se empezó a aplicar el impuesto sobre la renta. 
principalmente a la inversión en comunicaciones y transportes, que era el renglón dominante. El pequeño superávit de 1932 no fue posible mantenerlo en 1933, año en que se incurrió en un déficit moderado. A pesar de todo, los problemas del mercado de cambios orillaron a abandonar el patrón oro, y el peso fue devaluado en forma parecida a como había sido hecho en muchos paises industrializados. Como consecuencia, a partir de 1935 se inició el proceso inflacionario que continuó hasta 1956, proceso que dio lugar a tres nuevas devaluaciones del peso.

El producto bruto interno descendió $5.6 \%$ de 1929 a 1932. Las manufacturas, los transportes y la minería descendieron fuertemente. El petróleo simplemente continuó el descenso iniciado desde 1921. La ganadería, la energía eléctrica y el comercio fueron los sectores que menos resintieron la depresión.

El volumen de la producción agrícola, en buena medida compuesto por cultivos de subsistencia, no resintió tanto los efectos de la crisis -excepto, quizás, por lo que hace al algodón, en 1932. Los otros cultivos de exportación, o sea el henequén y el café, aparentemente con muy bajas elasticidades precio a corto plazo, mantuvieron las oscilaciones un tanto erráticas de sus niveles anteriores de producción.

La producción minera, casi toda para exportación, descendió como consecuencia de la caída de la demanda externa; en efecto, la producción de plomo bajó de 248.5 miles de toneladas en 1929 a 118.7 en 1933; la de plata descendió de 3381 toneladas en 1929 a 2118 en 1933.

Las manufacturas, cuya contribución al producto bruto interno disminuyó en $7.3 \%$, se recuperaron muy rápidamente, y para 1934 superaron los niveles previos a la depresión. La producción de textiles', calzado y tabaco casi no mostró descenso alguno; aunque sí lo hubo drástico en otros, más dependientes de insumos importados, como en el caso de los hilados y tejidos de lana. ${ }^{5}$ Se ha señalado que en otros países de América Latina (Argentina, Brasil, Colombia) la gran depresión estimuló la sustitución de importaciones y propició la industrialización. Sin embargo, a través de observaciones apareadas y de la prueba de $\mathrm{X}^{2}$ ( $j i$ cuadrada) se probó que para México no hubo cambio "significativo" en la estructura de las importaciones en el período inmediato posterior a la gran depresión; de lo que se deduce que en México la gran depresión no fue un factor de estímulo en el proceso de sustitución de importaciones. ${ }^{6}$

\section{Polfticas de fomento Del DESARRollo}

El periodo comprendido entre las dos guerras mundiales fue una época de importantes cambios institucionales que constituyeron condiciones necesarias del proceso de crecimiento sostenido ocurrido

- Secretaría de Economia, op. cit., pp. 47-52.

- Para esta prueba se utilizaron las series de la importación de mercancías por sectores de actividad económica (15 sectores). Se comparó (tanto en cifras absolutas como en porcientos del total importado) el período $1925-1929$ con el período 19341938 y tanto la prueba de $j i$ cuadrada como la de observaciones apareadas indicaron que no hubo cambio "significativo" en la estructura de las importaciones. 
de 1935 a la fecha. En este período se formó la base del actual sistema político, se acabó con el predominio de los caudillos militares y se organizó en el seno del partido oficial a obreros y campesinos; se reformó la política de gasto público para orientarla al fomento económico y social; se establecieron los fundamentos del sistema financiero con la fundación del Banco de México y las instituciones nacionales de crédito agrícola, industrial y de servicios públicos; se dio impulso a la reforma agraria y, finálmente, se nacionalizó el petróleo Y se creó la Comisión Federal de Electricidad, vinculando la inversión en energía a la actividad económica interna.

Entre las políticas de fomento del desarrollo que tuvieron lugar en el periodo entre las dos guerras mundiales, hay cuatro que pueden considerarse sumamente importantes: la reforma agraria, la expropiación petrolera, la creación de mecanismos financieros, y el uso del gasto público para la formación de capital. A las dos primeras, la reforma agraria y la expropiación petrolera, ya nos hemos referido en otro trabajo, ${ }^{7}$ por lo que en esta ocasión haremos referencia principalmente al cambio en la política de gasto público y a la creación de mecanismos financieros. La política de gasto público tuvo especial importancia en la época comprendida entre las dos guerras mundiales. El sistema financiero, por su parte, empezó a constituirse en esta época y alcanzó un período de auge y de influencia determinante como intermediario entre el ahorro y la inversión en la etapa de crecimiento con estabilidad.

\section{Cambios en lá politica de gasto público}

El primer cambio de orientación del presupuesto en gasto administrativo se produjo durante la presidencia de Alvaro Obregón, quien redujo el gasto administrativo proyectado a $59.2 \%$ del total, o sea entre 10 y $20 \%$ menos que las erogaciones de años anteriores; luego se redujo aún más drásticamente bajo Lázaro Cárdenas, y los fondos empezaron a ser canalizados en mayor proporción a fomento económico (obras públicas) y social,8 al mismo tiempo que se abandonó la anterior política de presupuesto equilibrado. En 1936 el presupuesto administrativo ${ }^{9}$ y el gasto realizado en este renglón bajaron a menos de la mitad del total, a $47.2 \%$ y $40.5 \%$, mucho menos que en cualquier época anterior. Manuel Avila Camacho continuó esta política cardenista, y para 1946 el gasto administrativo descendió al $38 \%$ del

7 Leopoldo Solís M., "Hacia un análisis general a largo plazo del desarrollo económico de México", Demografta Y Economta, Vol. I, Núm. 1, 1967, pp. 40-91. Los apartados referentes a la reforma agraria y a la expropiación petrolera se encuentran en las pp. 5459.

8 Ver James Wilkie, The Mexican Revolution: Public Expenditure and Social Change. Berkeley, University of California Press, 1967. Wilkie divide el gasto sederal en gasto administrativo, económico y social y analiza sus fluctuaciones tesde la época de Juárez. En este apartado nos referimos a la clasificación del gasto público que hace Wilkie, aclarando que dicha clasificación es diferente a la que presenta la Secretaría de la Presidencia (Dirección de Inversiones Públicas) en sus cuadros de destino de la inversión pública federal.

- Wilkie incluye en el gasto administrativo los gastos militares, pagos de la deuda pública, gastos de Hacienda, pensiones y otros gastos administrativos mecores (legislativo, presidencial, judicial, relaciones exteriores, etc.). 
presupuesto. La misma tendencia continuó en las dos administraciones posteriores. Miguel Alemán presupuestó $40 \%$ en gasto administrativo y Adolfo Ruiz Cortines lo hizo descender más aún, a $29.4 \%$. Posteriormente empezó a crecer de nuevo con Adolfo López Mateos.

El gasto de fomento económico ${ }^{10}$ ascendió en la administración de Cárdenas cuando se duplicó el porciento de este tipo de erogaciones, habiendo pasado del $20-25 \%$ de años anteriores a $37-40 \%$. Avila Camacho y Alemán lo hicieron ascender aun más, hasta que en 1952 constituyó el $56.9 \%$ en 1952 y el $57.9 \%$ en 1954. López Mateos dio un nuevo giro a la política de gasto e hizo descender el porciento gastado en fomento económico. Calles puso énfasis en el desarrollo del sector agropecuario más bien que en la distribución de la tierra, pero después se estableció la práctica, que se mantiene hasta la fecha, de repartir mucha tierra y dar menos importancia a los fondos destinados a mejorar la irrigación y la agricultura.

El gasto social ${ }^{11}$ ganó importancia con Cárdenas, habiendo llegado a $19.9 \%$ en 1938, lo que fue una cifra no rebasada hasta 1962 inclusive. La revolución económica posterior quitó relevancia a este tipo de gasto, que en 1940 ya sólo significaba el $11.9 \%$, porcentaje tan bajo como el de 1928. López Mateos le dio nuevo impulso y lo hizo alcanzar $22.6 \%$ en 1963.

La revolución orientada al cambio social produjo poco avance en este sentido. En cuanto a lo económico, la revolución auspiciada por el gobierno propició la formación de capital y coadyuvó a alcanzar el objetivo de un desarrollo económico acelerado. Asimismo, posteriormente facilitó la modernización social, que fue más rápida que la alcanzada con cualquier otro tipo de programa.

\section{La formación del sistema financiero}

Como consecuencia de la destrucción del sistema bancario durante la Revolución, en 1925 los activos de las instituciones financieras eran menores que los de antes de aquélla. Con relación al producto nacional bruto fueron más bajos aún, habiendo descendido de $1 / 3$ en 1910 a $1 / 5$ en 1925; y no fue sino hasta 1940 cuando volvieron a la proporción prerrovolucionaria.12 Un hecho de gran significación, resultante de la etapa armada de la Revolución, y cuya influencia llegó hasta fechas muy recientes, fue el periodo de inflación aguda de esta época, que contribuyó a la destrucción del sistema financiero, de tal manera que después se presentó un período de escasez de medios de pago y baja de precios previa a la gran depresión, que ésta después agudizó. (Véase el cuadro 2.) La destrucción del sistema financiero se aprecia con claridad en la cifra del crédito bancario, que descendió de $603 \mathrm{mi}$ -

10 Según Wilkie este renglón abarca agricultura e irrigación, crédito agrícola, comunicaciones y obras públicas, inversiones, y gasto económico no clasificado (industria y comercio, departamento agrario, turismo, etc.).

11 Para Wilkie el gasto social cubre educación, salud pública, bienestar y asistencia, agua potable y alcantarillado, trabajo, asuntos indígenas y gasto social no clasificado.

12 Raymond Goldsmith, The Financial Development of Mexico, OECD, París, 1966. 


\section{Cuadro 2}

Máxico: INDICADORES FINANCIEROS, 1895-1967

\begin{tabular}{|c|c|c|c|c|c|c|c|c|c|c|c|c|}
\hline Anós & & $\begin{array}{l}\text { Produoto } \\
\text { bruto 19 } \\
\text { terno } \\
\text { (procios } \\
\text { oorrienten) }\end{array}$ & $\begin{array}{l}\text { Produoto } \\
\text { por per- } \\
\text { cone (pe } \\
\text { vos de } \\
1950 \text { ) }\end{array}$ & $\begin{array}{l}\text { Hedsto olr } \\
\text { oulante } y\end{array}$ & Bal & Hetion $y$ & & $\begin{array}{l}\text { Cuente de } \\
\text { oheques a/ }\end{array}$ & $\begin{array}{l}\text { Modio ois } \\
\frac{\text { culente }}{\text { P. }_{\text {(x) }}{ }^{1 .}}\end{array}$ & $\begin{array}{l}\text { Ind 10e de } \\
\text { preoto dol ded } \\
\text { P. B. I. } \\
(1950.100)\end{array}$ & $\begin{array}{l}\text { Ioportan } \\
\text { otonos } a / b /\end{array}$ & $\begin{array}{c}\text { Reporta- } \\
\text { olonec }] / 0 /\end{array}$ \\
\hline $\begin{array}{l}1895 \\
1896 \\
1897 \\
1898 \\
1899 \\
1900 \\
1901 \\
1902 \\
1903 \\
1904 \\
1905 \\
1906 \\
1907 \\
1908 \\
1909 \\
1910\end{array}$ & & $\begin{array}{r}695 \\
742 \\
608 \\
855 \\
855 \\
1941 \\
1065 \\
1240 \\
1192 \\
1254 \\
1402 \\
1380 \\
1490 \\
1683 \\
1596 \\
1787 \\
1962\end{array}$ & $\begin{array}{r}519 \\
536 \\
564 \\
577 \\
602 \\
601 \\
648 \\
607 \\
667 \\
694 \\
709 \\
722 \\
746 \\
715 \\
733 \\
666\end{array}$ & $\begin{array}{r}33.4 \\
38.0 \\
46.5 \\
56.2 \\
64.6 \\
67.8 \\
77.6 \\
94.7 \\
92.5 \\
91.6 \\
122.8 \\
134.3 \\
129.4 \\
159.9 \\
179.4 \\
193.9\end{array}$ & & $\begin{array}{r}33.4 \\
38.0 \\
44.8 \\
54.4 \\
63.2 \\
64.0 \\
71.3 \\
86.1 \\
84.2 \\
83.5 \\
94.1 \\
97.8 \\
91.5 \\
87.5 \\
101.5 \\
113.6\end{array}$ & 1 & $\begin{array}{r}1.7 \\
1.8 \\
1.4 \\
3.8 \\
6.3 \\
8.6 \\
8.3 \\
8.3 \\
8.1 \\
28.7 \\
36.5 \\
37.9 \\
72.4 \\
77.9 \\
80.3\end{array}$ & $\begin{array}{r}4.81 \\
5.12 \\
5.75 \\
6.57 \\
6.87 \\
6.37 \\
6.26 \\
7.94 \\
7.38 \\
6.53 \\
8.90 \\
9.01 \\
7.69 \\
10.02 \\
10.04 \\
9.88\end{array}$ & $\begin{array}{l}10.6 \\
10.8 \\
11.0 \\
11.2 \\
11.6 \\
13.0 \\
13.9 \\
14.1 \\
13.3 \\
14.1 \\
13.5 \\
14.1 \\
15.3 \\
15.1 \\
16.2 \\
17.7\end{array}$ & $\begin{array}{l}42 \\
42 \\
44 \\
51 \\
61 \\
133 \\
151 \\
191 \\
178 \\
178 \\
220 \\
232 \\
222 \\
157 \\
195 \\
206\end{array}$ & $\begin{array}{l}105 \\
111 \\
129 \\
138 \\
150 \\
149 \\
160 \\
193 \\
197 \\
194 \\
271 \\
248 \\
243 \\
231 \\
260 \\
294\end{array}$ \\
\hline $\begin{array}{l}1921 \\
1922 \\
1923 \\
1924 \\
1925 \\
1926 \\
1927 \\
1928 \\
1929 \\
1930 \\
1931 \\
1932 \\
1933 \\
1934 \\
1935 \\
11936 \\
1937 \\
1938\end{array}$ & 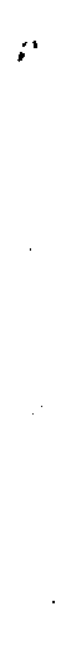 & $\begin{array}{ll}3 & 049 \\
3 & 198 \\
3 & 325 \\
2 & 867 \\
3 & 621 \\
4 & 087 \\
3 & 938 \\
4 & 112 \\
4 & 244 \\
4 & 317 \\
3 & 773 \\
2 & 821 \\
3 & 349 \\
3 & 506 \\
4 & 173 \\
5 & 058 \\
6 & 450 \\
6 & 818\end{array}$ & $\begin{array}{r}786 \\
842 \\
829 \\
830 \\
969 \\
1071 \\
998 \\
993 \\
989 \\
939 \\
951 \\
791 \\
904 \\
939 \\
997 \\
1062 \\
1101 \\
1102\end{array}$ & $\begin{array}{l}162.2 \\
200.7 \\
186.5 \\
214.6 \\
231.3 \\
233.2 \\
151.5 \\
224.3 \\
238.7 \\
275.6 \\
350.4 \\
356.2 \\
372.4 \\
481.2\end{array}$ & $\cdot$ & $\begin{array}{r}1.4 \\
1.8 \\
1.4 \\
2.3 \\
2.2 \\
1.2 \\
1.1 \\
37.3 \\
68.1 \\
86.2 \\
152.2 \\
136.3 \\
165.4 \\
257.7\end{array}$ & & $\begin{array}{l}160.8 \\
198.9 \\
185.1 \\
212.3 \\
229.1 \\
232.0 \\
150.4 \\
187.0 \\
170.6 \\
189.4 \\
198.2 \\
219.9 \\
207.0 \\
223.5\end{array}$ & $\begin{array}{l}4.48 \\
4.91 \\
4.73 \\
5.22 \\
5.45 \\
5.40 \\
4.02 \\
7.95 \\
7.13 \\
7.86 \\
8.40 \\
7.04 \\
5.77 \\
7.06\end{array}$ & $\begin{array}{l}27.0 \\
26.0 \\
27.1 \\
23.0 \\
24.4 \\
24.6 \\
25.0 \\
25.5 \\
26.3 \\
27.8 \\
23.6 \\
20.8 \\
21.3 \\
21.1 \\
23.2 \\
25.9 \\
31.4 \\
32.6\end{array}$ & $\begin{array}{l}493 \\
309 \\
315 \\
321 \\
391 \\
381 \\
346 \\
358 \\
382 \\
350 \\
217 \\
181 \\
244 \\
334 \\
406 \\
464 \\
614 \\
494\end{array}$ & $\begin{array}{l}757 \\
644 \\
568 \\
615 \\
682 \\
692 \\
634 \\
592 \\
591 \\
458 \\
400 \\
305 \\
365 \\
644 \\
750 \\
775 \\
892 \\
838\end{array}$ \\
\hline
\end{tabular}


Cuadro 2 (conclusion)

\begin{tabular}{|c|c|c|c|c|c|c|c|c|c|}
\hline AKOE & $\begin{array}{c}\text { Produoto } \\
\text { bruto in } \\
\text { terno } \\
\text { (procios } \\
\text { oorrientea) }\end{array}$ & $\begin{array}{l}\text { Produote } \\
\text { por per- } \\
\text { oone (pe } \\
\text { vos de } \\
1950 \text { ) }\end{array}$ & $\begin{array}{l}\text { Modio olr } \\
\text { culante }\end{array}$ & $\begin{array}{l}\text { Billeter } \\
\text { monede }]\end{array}$ & $\begin{array}{l}\text { Cuenta de } \\
\text { cheques a }\end{array}$ & $\frac{\text { Medio ois }}{\text { oulante }}$ & $\begin{array}{l}\text { Indtoe de } \\
\text { precioe del } \\
\text { P. B. I } \\
(1950-100)\end{array}$ & $\begin{array}{l}\text { Importa- } \\
\text { olones } \mathrm{a} / \mathrm{b} /\end{array}$ & $\begin{array}{l}\text { Exporta- } \\
\text { ciones } / / \mathrm{d} /\end{array}$ \\
\hline $\begin{array}{r}1939 \\
1940 \\
1941 \\
1942 \\
1943 \\
1944 \\
1945 \\
-1946 \\
1947 \\
1948 \\
1949 \\
11950 \\
1951 \\
1952 \\
1953 \\
1954 \\
1955 \\
-1956 \\
1957 \\
1958 \\
1959 \\
1960 \\
1961 \\
1962 \\
1963 \\
1964 \\
1965 \\
1966 \\
1967\end{array}$ & $\begin{array}{rr}7 & 563 \\
7 & 995 \\
8 & 939 \\
14 & 409 \\
12 & 646 \\
18 & 089 \\
19 & 890 \\
26 & 859 \\
29 & 995 \\
32 & 119 \\
35 & 512 \\
41 & 060 \\
53 & 026 \\
59 & 384 \\
58 & 963 \\
72 & 205 \\
88 & 218 \\
100 & 600 \\
115 & 542 \\
128 & 575 \\
137 & 665 \\
155 & 889 \\
165 & 671 \\
179 & 874 \\
194 & 845 \\
227 & 976 \\
246 & 200 \\
276 & 967 \\
306 & 075\end{array}$ & $\begin{array}{ll}1 & 171 \\
1 & 165 \\
1 & 221 \\
1 & 262 \\
1 & 268 \\
1 & 324 \\
1 & 328 \\
1 & 378 \\
1 & 394 \\
1 & 417 \\
1 & 463 \\
1 & 562 \\
1 & 635 \\
1 & 650 \\
1 & 604 \\
1 & 718 \\
1 & 810 \\
1 & 868 \\
1 & 945 \\
1 & 985 \\
1 & 976 \\
2 & 062 \\
2 & 064 \\
2 & 095 \\
2 & 154 \\
2 & 293 \\
2 & 334 \\
2 & 429 \\
2 & 560\end{array}$ & $\begin{array}{rr} & 882.3 \\
1 & 060.3 \\
1 & 269.3 \\
1 & 749.8 \\
2 & 672.9 \\
3 & 310.0 \\
3 & 543.0 \\
3 & 464.2 \\
3 & 473.5 \\
3 & 944.0 \\
4 & 605.0 \\
6 & 065.1 \\
6 & 873.1 \\
7 & 197.1 \\
7 & 683.7 \\
8 & 770.4 \\
110 & 757.8 \\
11 & 982.0 \\
12 & 762.8 \\
13 & 466.8 \\
15 & 582.8 \\
17 & 137.3 \\
18 & 0 c 7.6 \\
20 & 366.7 \\
23 & 699.1 \\
27 & 732.8 \\
29 & 605.8 \\
33 & 160.9 \\
35 & 489.0\end{array}$ & $\begin{array}{rr} & 597.7 \\
& 661.2 \\
& 797.2 \\
1 & 021.0 \\
1 & 477.5 \\
1 & 768.1 \\
1 & 662.4 \\
1 & 732.0 \\
1 & 757.2 \\
2 & 117.6 \\
2 & 378.4 \\
2 & 914.3 \\
3 & 457.7 \\
3 & 648.5 \\
3 & 863.6 \\
4 & 637.1 \\
5 & 084.1 \\
5 & 734.2 \\
6 & 093.5 \\
6 & 615.1 \\
7 & 250.3 \\
7 & 574.5 \\
8 & 275.4 \\
9 & 144.1 \\
10 & 263.8 \\
11 & 923.3 \\
12 & 506.7 \\
13 & 629.6 \\
14 & 748.7\end{array}$ & 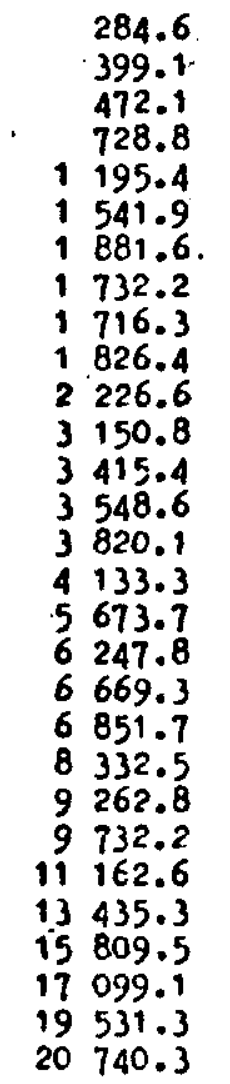 & $\begin{array}{l}11.67 \\
13.26 \\
14.20 \\
12.14 \\
21.14 \\
18.30 \\
17.81 \\
12.90 \\
11.58 \\
12.28 \\
12.97 \\
14.77 \\
12.96 \\
12.12 \\
13.03 \\
12.15 \\
12.19 \\
11.91 \\
11.05 \\
10.47 \\
11.32 \\
10.99 \\
10.87 \\
11.29 \\
12.16 \\
12.16 \\
12.03 \\
11.97 \\
11.59\end{array}$ & $\begin{array}{c}33.4 \\
{[34.9]} \\
35.6 \\
54.0 \\
45.9 \\
61.2 \\
65.3 \\
82.7 \\
88.8 \\
91.0 \\
94.9 \\
100.0 \\
119.9 \\
129.3 \\
128.1 \\
142.0 \\
159.5 \\
170.6 \\
182.2 \\
192.1 \\
199.9 \\
1210.0] \\
215.4 \\
222.8 \\
226.9 \\
241.0 \\
247.1 \\
258.3 \\
268.1\end{array}$ & $\begin{array}{ll} & 630 \\
& 669 \\
& 915 \\
& 753 \\
& 910 \\
1 & 895 \\
1 & 604 \\
2 & 637 \\
3 & 230 \\
2 & 951 \\
3 & 527 \\
4 & 807 \\
7 & 110 \\
6 & 983 \\
6 & 985 \\
8 & 926 \\
11 & 037 \\
13 & 395 \\
14 & 439 \\
14 & 108 \\
12 & 583 \\
14 & 831 \\
14 & 233 \\
14 & 289 \\
15 & 503 \\
18 & 662 \\
19 . & 503 \\
20 & 055 \\
21 & 853\end{array}$ & $\begin{array}{rr} & 914 \\
& 960 \\
& 730 \\
& 990 \\
1 & 130 \\
1 & 047 \\
1 & 272 \\
1 & 915 \\
2 & 162 \\
2 & 661 \\
3 & 623 \\
3 & 789 \\
4 & 630 \\
4 & 759 \\
4 & 442 \\
5 & 734 \\
7 & 773 \\
8 & 245 \\
7 & 318 \\
7 & 072 \\
7 & 534 \\
7 & 896 \\
7 & 582 \\
9 & 668 \\
10 & 369 \\
11 & 034 \\
12 & 491 \\
12 & 589 \\
12 & 302\end{array}$ \\
\hline
\end{tabular}

Fuente: Banco de México, S. A., Departamento de Estudios Económicos.

a En millones de pesos.

- Las importaciones de mercancías en el periodo 1895 a 1950 se identifican con la rama de origen de éstas. De 1950 a la fecha, las importaciones de mercancias se presentan por rama de destino.

c Las exportaciones desde el año 1895 a 1950 , están subvaluadas, como consecuencia de utilizar el valor declarado por los exportadores que tienden a disminuir el gravamen arancelario. De 1950 a 1967, se incluye la revaluación de los productos principales, efectuada por el Banco. 
llones en 1910 a 342 en 1925 y nuevamente a 245 en 1932. Otro tanto ocurre con las inversiones en valores en las mismas fechas. El nivel de 1910 no se vuelve a alcanzar hasta 1937, aunque el de este último año resulta inferior en términos reales por el cambio de precios, los cuales ascendieron de 18.9 en $1910(1950=100)$ a 24.4 en 1925 y 31.4 en 1937 (véase el cuadro 2), y más aún en términos relativos por el zumento del producto nacional monetario. La relación de medio circulante a producto bruto interno muestra la destrucción de medios de pago de 1910 a 1925, y el muy bajo nivel de liquidez existente durante los veintes (véase el cuadro 2), que probablemente constituye la explicación del descenso de precios de esa época. El cuadro 3 señala la elasticidad-ingreso de la oferta monetaria, que muestra la rápida monetización ocurrida durante el Porfiriato, la destrucción durante la Revolución y la ganancia de liquidez después de la depresión durante la segunda guerra mundial, hasta alcanzar su nivel cercano a la unidad desde el fin de la guerra al presente.

\section{Cuadro 3}

México: Relación entre el producto bRUTO interno Y el Medio Circulante, 1895-1955

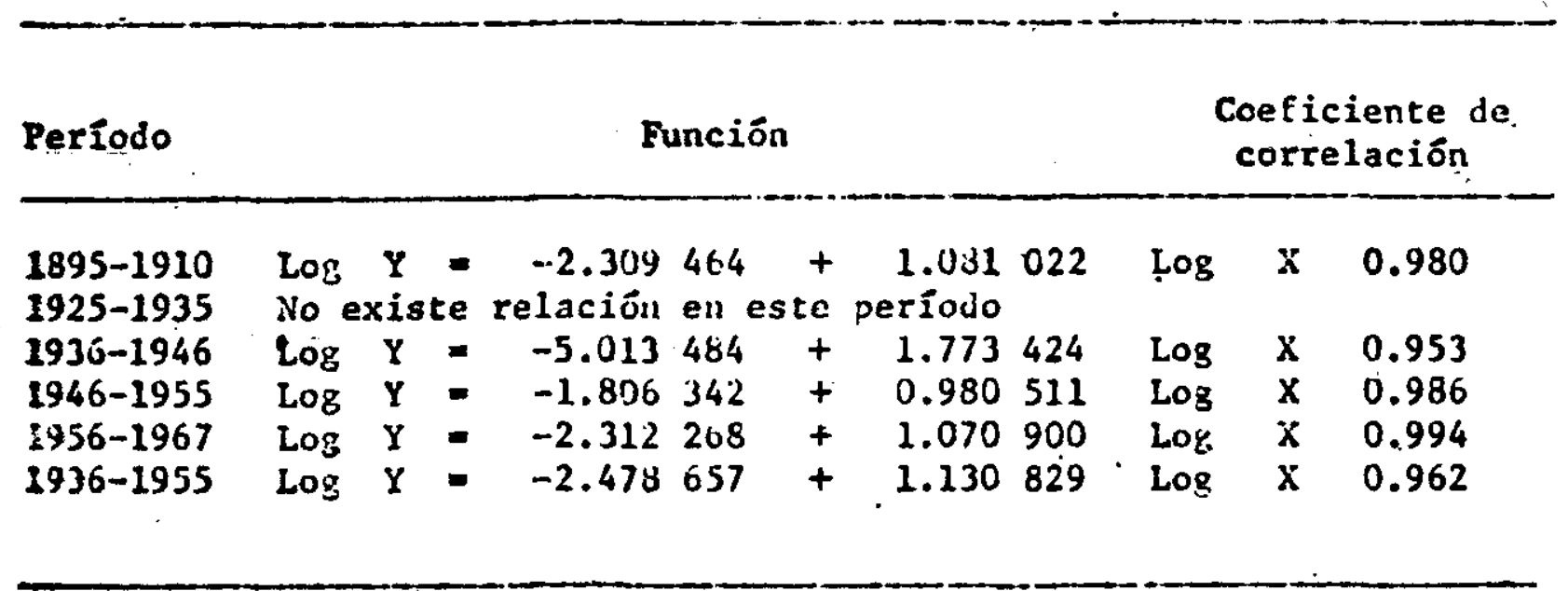

Fuente: cuadro 2.

$\mathbf{X}=$ Producto bruto interno.

$\mathbf{Y}=$ Medio circulante.

Desde ta fundación del Banco de México en 1925 hasta bastante después de la segunda guerra mundial los bancos comerciales fueron las instituciones financieras más importantes, aunque su crecimiento fue de sólo $2.3 \%$ al año entre 1925 y 1940 . Sin embargo, su número aumentó, y los créditos a corto plazo para financiar el comercio interior y exterior significaron unas 3/4 partes de los recursos totales de estas instituciones. Aunque en 1940 los precios eran todavía muy parecidos a los de 1920 , el crédito ya superaba en más del doble los niveles de 1925. Los valores èrán más de cuatro veces los del año inicial.

La cantidad de medio circulante en 1925, 162.2 millones de pesos, fue menor que en 1910, 193.9 millones, en tanto que el índice de precios habia ascendido $1.7 \%$. Los billetes prácticamente desaparecieron de la circulación entre 1910 y 1925, aunque las cuentas de cheques se duplicaron. No fue hasta 1933 cuando empezaron a circular nueva- 
mente. Las cuentas de cheques, a su vez, ascendieron de 1925 a 1930, y descendieron de este año a 1932. En resumen, en la fase descendente de la gran depresión tanto los precios como los medios de pago bajaron y no es sino hasta después de 1935 cuando ambos inician una etapa de crecimiento, en la cual, sin embargo, los medios de pago ascienden a mayor velocidad que los precios y aumentan en términos reales. Esta tendencia cubre todo el periodo de crecimiento con inflación que termina en 1957, y se acentúa a partir de ese año. El hecho que se desea destacar es que la destrucción del incipiente sistema financiero por la Revolución fue muy grave para el desarrollo de una economía de mercado, ya que dificultaba las transacciones económicas y el avance de la comercialización de bienes y servicios, y, por lo tanto, del tamaño del mercado. Aparte de que la disminución de la liquidez dificultaba los pagos y las transacciones, la falta de un mercado de dinero y capitales impedía a los empresarios obtener préstamos con qué establecer o ampliar sus empresas, lo que obstaculizaba la formación de capital y dificultaba que los fondos fluyeran hacia las empresas y actividades de más alta productividad.

Un reşultado de estas condiciones fue la modificación de la pro porción de la riqueza nacional correspondiente a la inversión extranjera en los años de inestabilidad política. La riqueza nacional, según Goldsmith, ${ }^{13}$ se elevó de 3.90 miles de millones de pesos en 1900 a 10.03 en 1929. La inversión extranjera ascendió de 1.35 a 4.0 miles de millones (3.50 en 1926 y 3.40 en 1911); su participación aumentó del $20 \%$ en 1906 al $40 \%$ en 1929. Esto confirma la apreciación de Butler Sherwell de que la importancia de la inversión extranjera aumentó durante la Revolución y el período inmediato posterior.

Los activos de las instituciones financieras constituían en 1910 el $10 \%$ de la riqueza nacional; en 1925 descendieron al $8 \%$, y ascendieron al $13 \%$ en 1937. Según las cifras de Goldsmith, como proporción del producto bajan del $32 \%$ al $16 \%$ en esos años, y suben el $39 \%$ en 1937, proporción que mantienen hasta 1955, cuando empiezan a ascender, una vez transcurridos varios años de estabilidad de los precios y del tipo de cambio; es a partir de entonces cuando los coeficientes financieros muestran un aumento sumamente rápido.

\section{El CRECIMIENTO CON INFLACIÓN Y EL CRECIMIENTO CON ESTABILIDAD}

Aunque las cifras del producto nacional del periodo anterior a 1940 son deficientes, es posible formarse una idea de la evolución del ingreso por persona en el presente siglo, y de lo que significa el período 1920-1940 en la perspectiva a largo plazo. En 1895-1910 el producto por persona creció al $2.7 \%$ anual. (Véase el cuadro 2.) En el lapso siguiente, 1910-1921, que cubre la etapa armada de la Revolución, el producto por persona presentó un ligero aumento de $0.2 \%$. En el período inmediato posterior, 1921-1935, que comprende la gran depresión, la tasa de crecimiento del producto por persona fue de $1.7 \%$, que resulta del $3.4 \%$ de incremento del producto disminuido por el aumento de la población. A partir del término de la gran depresión se

13 Goldsmith, op. cit. 
inicia una etapa de crecimiento vigoroso. El producto por persona crece al 2.9\% en los siguientes 32 años, 1935-1967 (al 3\% anual el producto por persona se duplica cada 23 años). Este período, sin embargo, cubre dos lapsos fácilmente identificados, uno de crecimiento con inflación, 1935-1956, y otro de crecimiento con estabilidad de precios y de tipo de cambio, que comprende de 1956 al presente.

Los precios, que habían ascendido durante el Porfiriato debido a la depreciación de la plata, subieron más rápidamente aún hasta 1918, como resultado de la inflación provocada por las emisiones de los distintos grupos armados. Pero de 1918 a 1932 el nivel de precios descendió; en términos de dólares los precios bajaron más rápidamente, ya que el peso disminuyó de valor. Fue al término de la depresión cuando los precios empezaron a ascender para formar la primera fase de las dos que comprende el período reciente de crecimiento de la economía mexicana; la primera de desarrollo con inflación, 1935-1956, con aumento de precios de $10 \%$ anual e inestabilidad cambiaria; y la siguiente, de desarrollo con estabilidad, en que los precios aumentaron al $3.9 \%$ anual, caracterizada por la estabilidad cambiaria y el auge financiero.

\section{Cuadro 4}

Méxco: Tasas medias de INCremento andal deL producto bruto interno, 1895-1967

(Pesos de 1950)

\begin{tabular}{|c|c|c|c|c|c|c|c|c|}
\hline Período & $\begin{array}{c}\text { Total } \\
.\end{array}$ & $\begin{array}{l}\text { Agri } \\
\text { cultul } \\
\text { ra }\end{array}$ & Gana & Mine & $\begin{array}{l}\text { Petro } \\
\text { leo }\end{array}$ & $\begin{array}{l}\text { Manu } \\
\text { fac } \\
\text { tura }\end{array}$ & $\begin{array}{l}\text { Cons } \\
\text { truç } \\
\text { ciôn }\end{array}$ & $\begin{array}{l}\text { Energía } \\
\text { eléctri } \\
\text { ca }\end{array}$ \\
\hline $\begin{array}{l}1895-1910 \\
1921-1933 \\
1935-1945 \\
1935-1956 \\
1946-1956 \\
1957-1967\end{array}$ & $\begin{array}{l}4.0 \\
3.4 \\
5.4 \\
5.8 \\
6.1 \\
6.2\end{array}$ & $\begin{array}{l}4.4 \\
5.1 \\
2.8 \\
4.9 \\
7.6 \\
3.8\end{array}$ & $\begin{array}{l}1.2 \\
4.7 \\
1.9 \\
2.9 \\
4.2 \\
4.2\end{array}$ & $\begin{array}{l}5.5 \\
4.4 \\
1.1 \\
1.2 \\
1.4 \\
1.6\end{array}$ & $\begin{array}{r}-7.1 \\
0.3 \\
4.7 \\
9.8 \\
7.6\end{array}$ & $\begin{array}{l}4.9 \\
3.8 \\
7.7 \\
7.5 \\
8.2 \\
3.0\end{array}$ & $\begin{array}{r}6.3 \\
6.8 \\
10.0 \\
8.7 \\
8.1 \\
7.4\end{array}$ & $\begin{array}{r}18.7 \\
12.1 \\
4.0 \\
6.5 \\
9.8 \\
9.4\end{array}$ \\
\hline
\end{tabular}

Fuente: con base en el cuadro 1.

Desde 1935 la inflación caracterizó a la economía mexicana. Hasta 1956 su tasa media de crecimiento anual fue de $10 \%$. Los movimientos de precios cambiaron considerablemente durante las distintas tases del período de inflación. Hubo fluctuaciones bastante bruscas, más aceleradas durante la guerra y los períodos posdevaluatorios. En 1956-1967 los aumentos de los precios descendieron asintóticamente hasta ser bastante moderados y asociarse, positivamente, a las tasas de crecimiento del producto nacional real. (Véase el cuadro 2.)

En el período 1935-1940, la reforma agraria, los gastos públicos y Las alzas de los salarios influyeron en la distribución del ingreso y en el nivel y la estructura del gasto, condicionando inicialmente una alta elastieidad-ingreso de la función consumo. Este hecho fortaleció; por el lado de la demanda, el desarrollo ocurrido durante la guerra 
-estimulado por cambios de la demanda externa-, si bien este efecto se fue debilitando en las postrimerías de la contienda y en la posguerra inmediata, como resultado de un cambio regresivo en la distribución del ingreso. Así, en su origen, la inflación tuvo características mixtas de alza de costos y de incrementos de demanda - la primera reforzada por el aumento de precios de las importaciones, que fue de $8.4 \%$ anual en 1941-1947. El comienzo del proceso inflacionario quizá caracterice su comportamiento posterior: el sector público se allegó recursos con medios inflacionarios para invertir en obras de infraestructura, es decir, en la formación de capital, ampliando la dotación de un factor escaso. Las obras públicas constituyeron un factor inflacionario en tanto que demandaban factores, generaban gastos y presionaban la capacidad productiva, lo que se traducía en costos crecientes. En condiciones de financiamiento altamente inflacionario, éste lo era aún más debido al largo período de gestación de las obras públicas.

Los precios agrícolas e industriales no se movieron paralelamente. Pese al avance de la producción agrícola, en 1935-1940 aumentaron a ritmo mucho más rápido los precios de los productos agrícolas que los industriales, probablemente, según se explica más adelante, por la redistribución de ingresos que produjo el reparto agrario y que aumentó la demanda de alimentos.

\section{Cuadro 5}

México: TASAS MIEDIAS DE INCREMENTO DE LOS PRECTOS, 1935-1965

\begin{tabular}{ccc}
\hline Periodos & $\begin{array}{c}\text { Precios } \\
\text { agricolas }\end{array}$ & $\begin{array}{c}\text { Precios } \\
\text { industriales }\end{array}$ \\
\hline $1935-1940$ & 8.5 & 3.9 \\
$1940-1945$ & 15.6 & 15.5 \\
$1945-1950$ & 9.1 & 8.8 \\
$1950-1955$ & 4.8 & 7.8 \\
$1955-1960$ & 5.3 & 4.4 \\
$1960-1965$ & 4.5 & 2.5 \\
\hline
\end{tabular}

Fuente: Banco de México, S. A.

\section{Agricultura}

La agricultura, que había estado estancada desde finales del Porfiriato, y durante éste por lo que se refiere a los cultivos de consumo interno, inició un genuino proceso de desarrollo a partir de 1935, como resultado de la inversión pública en obras de fomento agropecuario y comunicaciones y del más amplio uso de la tierra que resultó de la reforma agraria. Al término de la gran depresión se inicia una fase de aceleración del crecimiento económico, caracterizada principalmente por el desarrollo de la agricultura y de las manufacturas. La agricultura, que había crecido al $4.4 \%$ anual en 18951910 , y al $5.1 \%$ anual en 1921-1935, asciende al $2.8 \%$ anual en 1935-1945 y se acelera al $7.6 \%$ anual en 1946-1956, tasa superior a la del pro- 
ducto nacional total. Asimismo, se manifiestan algunos cambios en la estructura de la producción agrícola. Los alimentos, que en 1925-1929 constituían el $88.5 \%$ de los artículos comprendidos en el índice de producción agrícola de la CEPAL, se redujeron al $68.7 \%$ en 1945-1947, a pesar de que su producción ascendió $31.2 \%$. Sin embargo, algunos productos crecieron algo más rápidamente: las oleaginosas, las frutas, el algodón, la caña de azúcar, etc. El maíz y el trigo empezaron a migrar regionalmente, moviéndose del centro del país a las nuevas zonas de riego, con aumento de sus rendimientos; entre 1924-1925 y 1947-1948 la participación de las tierras cultivadas con trigo en el centro de la República disminuyó del $54 \%$ al $35 \%$ del total.

Al final de la grán depresión se inicia una fase de desarrollo de la economía mexicana impulsado por el crecimiento de la agricultura, la cual, al producir más rápidamente que los cambios de la demanda interna, aumentó en forma considerable las exportaciones de productos agrícolas. En efecto, de 1935 a 1956 estas ventas aumentaron a una tasa media anual de $8.9 \%$, habiendo pasado de significar el $31.6 \%$ de las exportaciones totales en $1910-1911$, al $3.3 \%$ en 1920 , al $7.6 \%$ en 1935 y al $20.3 \%$ en 1945 .

El hecho es que la agricultura creció muy rápidamente durante todo el período de desarrollo con inflación, e inclusive en 1946-1956 avanzó a una tasa más rápida, $7.6 \%$ que la de crecimiento del producto total, $6.1 \%$. Esto tuvo un efecto bien definido sobre la balanza de pagos, según se explica más adelante. Durante el último período que aquí se distingue, 1957-1967, el crecimiento de la agricultura disminuye a la mitad de la velocidad de antes, $3.8 \%$.

\section{Industria}

La industria, en cambio, manifiesta un comportamiento casi opuesto al de la agricultura. ${ }^{14}$ El petróleo descendió en 1921-1935, se estancó hasta 1946, y de ahí en adelante aceleró su crecimiento hasta alcanzar tasas muy altas, superiores por un amplio margen a las del producto nacional. La energía eléctrica creció lentamente en 1935-1945, pero de ahí en adelante aceleró mucho su crecimiento, hasta que en 1957-1967 aumentó a la muy rápida tasa de $10.4 \%$ anual.

Las manufacturas fueron acelerando gradualmente sus tasas de crecimiento: $7.7 \%$ anual en $1935-1945,8.2 \%$ en $1946-1956$, tasa poco superior a la de la agricultura en el mismo lapso de desarrollo con inflación, y $8.0 \%$ en 1957-1967, más del doble del crecimiento agrícola en la fase de estabilidad de precios. Así, podemos caracterizar estos dos períodos de avance económico: como la fase inflacionaria, con fortalecimiento de la agricultura, crecimiento de las exportaciones agrícolas y desarrollo propulsado por el sector externo, y con el sistema muy abierto y orientado hacia afuera; y la fase de estabifidad, con muy lento avance de la agricultura y sus exportaciones, en la cual, como casi no se exportan manufacturas, se produce un fuerte crecimiento industrial a base de sustitución de importaciones, cerrán-

14 La mineria apenas si creció de 1935 a 1967. 
dose el sistema económico y volviendo a un desarrollo orientado hacia adentro.

\section{Balanza de pagos}

Por supuesto, las distintas fases de desarrollo imprimieron su marca en la balanza de pagos, tanto en la cuenta corriente como en la de capital.

Las exportaciones de productos agrícolas, que habían sufrido un colapso durante la Revolución y nuevamente en la gran depresión, ascendieron muy rápidamente después de esta última, como resultado del auge agrícola que siguió a la etapa activa de distribución de tierras y de inversiones en obras de fomento agropecuario.

En cambio, en el período de estabilidad de precios, 1957-1967, el menor aumento del producto agrícola, $3.8 \%$, motivó el más lento crecimiento de las exportaciones agrícolas, $4.0 \%$. Las exportaciones de bienes industriales fueron insignificantes durante todo el período.

Como puede apreciarse en el cuadro 6, en el período 1936-1945 (que comprende la segunda guerra mundial), la elasticidad-ingreso de las exportaciones es sorprendentemente baja (0.289), mientras que en el siguiente (1946-1955) aumentó considerablemente (1.12), para luego disminuir a 0.57 en el período de crecimiento con estabilidad.

Las importaciones, que se habian mantenido a un nivel constante durante los veintes, disminuyeron drásticamente durante la gran depresión, hasta 1932. El nivel de 1930 fue excedido nuevamente en 1935. Debe considerarse que la recesión de 1937-1938 las hizo descender nuevamente cuando se venían recuperando de los efectos de la gran depresión. ${ }^{15} \mathrm{La}$ elasticidad-ingreso de las importaciones fue bastante más elevada durante el Porfiriato. Descendió de 1.26 en 1946-1955, a 0.46 en 1956-1967 (véase el cuadro 6). De esta manera, la elasticidadingreso de las importaciones fue descendiendo conforme la industrialización sustituía importaciones y fue posible sostener la misma tasa de crecimiento con una menor de ingreso de divisas en cuenta corriente. También es cierto que hubo que recurrir al financiamiento externo en mucha mayor medida que antes, cosa especialmente cierta durante el período de estabilidad de precios. En consecuencia, los intereses de la deuda externa ganaron importancia en los egresos de la cuenta corriente, lo que sumado a las mayores remisiones de utilidades, dividendos y regalías de la inversión extranjera, hizo descender la disponibilidad de divisas provenientes en cuenta corriente una vez deducidos los pagos a los factores del exterior, por lo que se hizo necesario utilizar en forma creciente el crédito externo.

Parece contradictorio el hecho de que durante el periodo de inflación e inestabilidad cambiaria las exportaciones crecieran más rápidamente $y$ que en el de estabilidad su comportamiento fuera menos favorable. La estabilidad se logró y afianzó bajo condiciones de balanza de pagos más difíciles que antes; pero debe recordarse que la política

16 Esto fue especialmente cierto por lo que hace a los bienes de capital y los automóviles. 


\section{Cuadro 6}

México: Relaciones ENTRE el Producto bRUTO INTERNo, LA IMPORTACIÓN Y LA EXPORTACIÓN TOTAL DE MERCANCIAS, 1895-1955

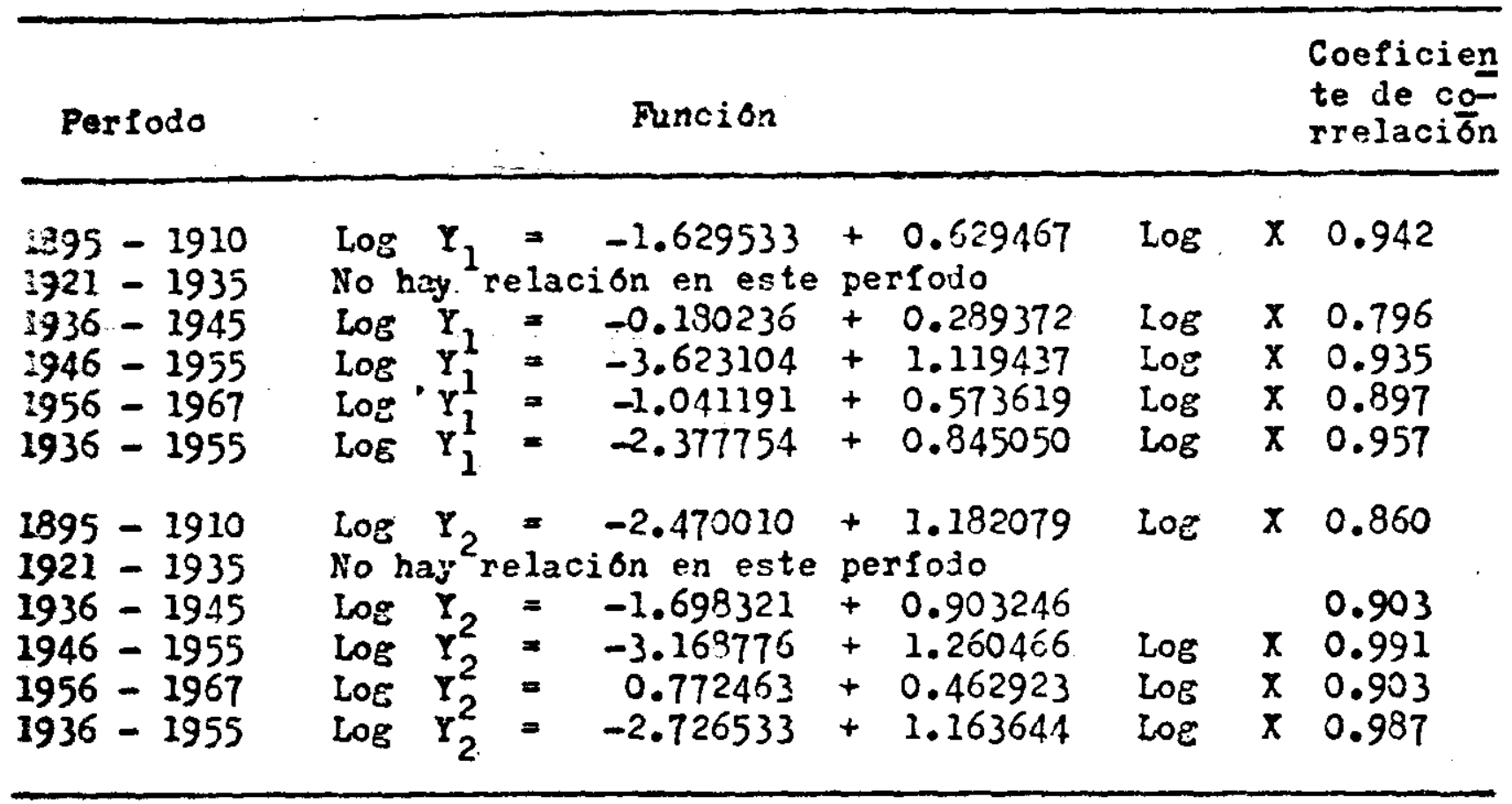

Fuente: con base en el cuadro 2.

$\mathbf{Y}_{\mathbf{1}}=$ Exportación total de mercancías a precios corrientes.

$\mathbf{Y}_{2}=$ Importación total de mercancias a precios corrientes.

$\mathbf{X}=$ Producto bruto interno a precios corrientes.

fiscal y monetaria actuó en forma muy distinta en ambos lapsos. A explicar este hecho dedicaremos el resto de este trabajo.

\section{Politica fiscal y monetaria}

La devaluación de 1938 estuvo asociada con la expropiación petrolera; la de 1948 se consideró como parte del ajuste mundial de paridades que ocurrió en la posguerra. ${ }^{16}$ En cambio, la de 1954 constituyó un hecho aislado que afectó drásticamente las expectativas nacionales. Fue nuevamente precipitada por el gasto público realizado esta vez por una nueva administración empeñada en contrarrestar el abatimiento temporal de la actividad económica debido a la recesión norteamericana de 1953 subsiguiente al fin de la guerra de Corea, cuando además se había reducido el precio de las materias primas que México exportaba. La agudización temporal del déficit gubernamental, financiado una vez más por el Banco de México, dio lugar a pérdida de reservas internacionales, hasta que la devaluación, que fue calificada de medida preventiva, situó el tipo de cambio a su actual aivel de 12.50 pesos por dólar. La modificación del valor externo del peso permitió aumentar los impuestos al sector exportador (con un gravamen ad valorem de $30 \%$ ), equilibrar el presupuesto, obtener superávit en 1955 y suspender la presión inflacionaria del sector pú-

\footnotetext{
16 Timothy D. Sweeney; "La balanza de pagos en México, 1949-1950", El Trimestre Económico, Vol. XX (4), Núm. 80, octubre-diciembre de 1953, pp. 642-675.
} 
blico por el lado de la demanda - que era la causa más importante de inflación. Hizo posible asimismo aliviar la pérdida de ingreso real del sector agrícola de exportación que resultaba de la baja de precios en el mercado internacional de las materias primas. Esto influyó en los precios internos de los productos agrícolas -que estaban ligados a los del mercado mundial-, alterando los precios relativos agrícolas-industriales.

Desde principios de la década de los cincuentas habían empezado a influir en el aumento del produçto agrícola la investigación y las obras de riego iniciadas en años anteriores, de manera que hacia 1952 se aprecia el comienzo de una clara tendencia al aumento de los rendimientos por hectárea. Dicho en otra forma, la elasticidad de la oferta agrícola aumentó. Cabe recordar que en el lapso 1946-1956 el producto agrícola creció a una tasa más acelerada que la del producto global; en cambio, en razón de la ley de Engel, la demanda de productos agrícolas crecía a menor tasa que la del producto global. La modificación de la estructura de precios relativos significó que las materias primas de origen agropecuario utilizadas por el sector industrial disminuyeron de precio; al mismo tiempo que, frente al menor costo de los insumos, se mantuvo fortalecida, al menos parcialmente, la posición de utilidades de la industria, para la cual el efecto alentador de la inflación empezaba a declinar. El bajo costo de los insumos proporcionados por el sector público reforzó ese elemento. Por otra parte, la anterior redistribución de los pagos a los factores en favor de las utilidades tendía a disminuir la elasticidad-ingreso del consumo y a estimular el ahorro, y constituía otro factor de abatimiento de la presión inflacionaria. Así, el desarrollo industrial se vio favorecido, a partir de esta etapa, con bajas en los precios relativos de las materias primas y otros insumos. La mayor accesibilidad al crédito de que gozó el sector industrial coadyuvó a sostener un alto nivel de inversión industrial que hizo más flexible su oferta productiva y facilitó el proceso, afirmado más tarde, de una tasa de crecimiento industrial superior a la agrícola, es decir, más de acuerdo con la estructura de la demanda y con sus elasticidades-ingreso. En resumen, el sistema económico había adquirido, en el sector agropecuario y en el industrial, una mayor flexibilidad productiva. Todo esto se conjugó con el uso más amplio de créditos del exterior. Siendo el nivel de la deuda externa bastante bajo en esas fechas, se pudo aumentar el endeudamiento e incrementar las importaciones y la oferta total sin presionar la demanda global, a pesar de que se aumentó la inversión pública; el caso es que temporalmente el financiamiento del banco central se sustituyó con financiamiento externo. En estas condiciones, la depreciación monetaria de 1954 fue un elemento de inflación transitorio, toda vez que las variables económicas que influían en el nivel de precios ya se comportaban con tendencia al equilibrio en condiciones de crecimiento con estabilidad.

La estabilidad de precios prevaleció finalmente, y la posterior reacción dinámica del ahorro en instituciones financieras iniciada en 1958, una vez que se modificaron las expectativas de precios, facilitó el financiamiento de los nuevos déficit gubernamentales con ahorros privados como complemento del endeudamiento externo. En este proceso 
fue de gran importancia el mayor uso de los encajes de reserva y el control selectivo de crédito a los intermediarios no monetarios, ${ }^{17}$ que fueron las instituciones que crecieron con mayor velocidad. Esto facilitó al banco central la captación de ahorros genuinos para financiar inversiones públicas. En resumen, la expansión monetaria fue sustituida por el uso de ahorro externo e interno.

Ya señalábamos que el crédito al sector oficial constituyó la causa determinante de la expansión monetaria durante los períodos de la guerra y de la posguerra considerados conjuntamente. Sin embargo, como proporción de la inversión pública, muestra una fase descendente que termina en 1952; otra carente de tendencia hasta 1962; y, durante el periodo đe estabilidad, una última de ascenso hasta alcanzar nuevamente las proporciones registradas durante el período de inflación de la guerra; pero entonces el rápido crecimiento financiero hizo manejable su financiamiento con ahorros privados. Los saldos de financiamiento al sector oficial en proporción a la inversión pública descendieron en el período de inflación hasta llegar a un nivel constante de $60 \%$ aproximadamente, que se alcanzó casi cinco años antes de iniciarse la estabilidad de precios. Cuando ésta se logró, el peso del financiamiento del déficit del sector público se fue transfiriendo primero del banco central a los bancos comerciales y después de éstos a los intermediarios no monetarios. De esta manera, el financiamiento bancario del sector oficial descendió primero en relación con la inversión pública y el producto interno, y más tarde pasó del tipo de financiamiento a base de expansión monetaria a la captación de ahorros genuinos canalizados por los intermediarios no monetarios, con lo que el impacto inflacionario del déficit gubernamental fue aminorándosé. En el período de estabilidad el financiamiento de la inversión pública fue apoyado adicionalmente con mayor uso de ahorro externo.

La inflación mexicana fue propicia al desarrollo económico por la naturaleza del déficit gubernamental, que se produjo como resultado de la inversión pública y tuvo como consecuencia un ensanchamiento de la infraestructura productiva, mejores transportes, amplia disponibilidad de combustibles y energía y mayor elasticidad de la oferta agrícola. Aunque el período de gestación de las obras públicas fue prolongado, sirvió a la larga para hacer más flexible la oferta de bienes y servicios. En algunos países el déficit se forma con transferencias al consumo; por ejemplo, a través de subsidios al sistema de transportes o a los gastos de seguridad social, con igual efecto en la presión inflacionaria y sin influir en el comportamiento de la oferta. La intermediación financiera se ajustó mediante la política monetaria para facilitar fondos prestables a los inversionistas, con el fin de que el desarrollo de un sector no se viera entorpecido por carencia absoluta de fondos de inversión o precisado a aumentar los recursos de autofinanciamiento con elevaciones de precios, que agravan el proceso inflacionario.

Los instrumentos de política fiscal creados constituyeron medios

it A. Ruiz E. y Leopoldo Solís, Aspectos generales de los instrumentos de politica moneteria y crediticia en México, CEMLA, IX Reunión Operativa, Buenos
Aires, 1966 . 
para determinar el nivel y destino de la inversión pública; asimismo, con la política monetaria se logró la reasignación de fondos prestables para apoyar un mayor gasto en inversión. Estos instrumentos permitieron mejorar la asignación de factores productivos; facilitaron a la industria y a la agricultura el acceso al crédito institucional y al uso de créditos externos para fines de desarrollo; hicieron posible crear el mercado de capitales, es decir, un mecanismo de colocación de deuda y de captación de ahorro interno; y proporcionaron los estímulos fiscales y de política comercial necesarios para la sustitución de importaciones, que favoreció el crecimiento industrial.

En realidad, el período de transición de inflación a estabilidad tiene en sí poca importancia, ya que el abatimiento de la inflación se explica por los cambios ocurridos durante la época anterior, principalmente por los desplazamientos de la función producción, el cambio en la estructura del consumo, y el aumento de la propensión a ahorrar, en el cual la suspensión del déficit gubernamental, primero, y su distinto financiamiento después, sólo fueron un corolario. Todo indica que durante la época de inflación se realizaron los cambios institucionales, se forjaron los instrumentos de política económica y se modificó el comportamiento de las variables que hicieron posible la etapa posterior de desarrollo con estabilidad. Los cambios institucionales consistieron básicamente en la mayor movilidad, tanto del uso de la tierra como del capital y de la mano de obra; asi como en la elevación del nivel educativo y, por consiguiente, la creación de la capacidad de absorción de adelantos tecnológicos y el fortalecimiento de la clase empresarial. Influyeron también favorablemente el mayor volumen de la inversión interna, la menor dependencia del exterior en el comercio de mercancías, y la monetización y mayor vinculación de la economía entre sus distintos elementos.

El papel preciso que jugó la política económica durante la época de transición no es fácil de esclarecer. Si bien la devaluación de 1954 permitió gravar más los mayores ingresos en pesos de los exportadores, anular el déficit presupuestal y limitar las exigencias de la demanda, por otra parte elevó el precio en pesos de las importaciones y aumentó mucho la tasa real de interés. Los primeros años de estabilidad de precios se vieron acompañados de un virtual estancamiento de la inversión privada, lo que no es de extrañar si se considera el alza de la tasa real de interés. Cierto es que la autoridad monetaria se adhirió a su vieja política de mantener fijos los precios en el mercado de bonos, impidiendo que el aceleramiento en el ahorro canalizado a instituciones financieras - resultante de la estabilidad de precios-presionara a la baja de la tasa de interés y que se reanimara la inversión privada. La tasa real de interés dejó de ser muy baja y negativa y posteriormente llegó a promediar el $13-15 \%$ real, efectivo anual.

Durante los primeros años de la administración de López Mateos el producto nacional aumentó a tasas menores que su crecimiento secular, por lo que se expresó mucho la opinión de que la estabilidad se había logrado a costa del desarrollo económico del país. Autores que escribieron sobre la economía mexicana en esa época, influidos por los acontecimientos del momento, compartieron la tesis del estan- 
amiento económico.18 Sin embargo, el sostenido crecimiento de la inversión pública, y su influencia en el aumento de la demanda gla aal, desembocó finalmente en un nuevo aumento de la inversión privada que, aunado a una nueva alza de las exportaciones, originó el aceleramiento de la tasa de crecimiento del producto nacional, habiéndose alcanzado en todo el período 1957-1967 una tasa de aumento del producto de $6.2 \%$, ligeramente mayor al ritmo de crecimiento que la economía mexicana logró en la época de inflación; si bien es cièfto que el aumento más rápido de la población dio como resultado un menor avance del ingreso per capita durante ese periodo.

18 Por ejemplo, véase Raymond Vernon, The Dilemma of Mexico's Development: The Roles of the Private and Public Sectors, Cambridge, Massachusetts,
Harvard University Press, 1963. 